\title{
Hypervalent Carbon Atoms in a Ferrocene Dication Derivative - $\left[\mathrm{Fe}\left(\mathrm{Si}_{2} \mathrm{C}_{5} \mathrm{H}_{2}\right)_{2}\right]^{2+}$
}

Venkatesan S. Thimmakondu*

Department of Chemistry and Biochemistry, San Diego State University, San Diego, CA 92182-1030, USA

Received July 12, 2021; E-mail: vthimmakondusamy@sdsu.edu

\begin{abstract}
Pentacoordinate carbon atoms are theoretically predicted here in a ferrocene dication derivative in both staggered$\left[\mathrm{Fe}\left(\mathrm{Si}_{2} \mathrm{C}_{5} \mathrm{H}_{2}\right)_{2}\right]^{2+}\left(\mathbf{1} ; C_{2 h}\right)$ and eclipsed-[Fe $\left.\left(\mathrm{Si}_{2} \mathrm{C}_{5} \mathrm{H}_{2}\right)_{2}\right]^{2+}(\mathbf{2} ;$ $C_{2 v}$ ) forms for the first time. The barrier between these two ranges from -38.11 to $4.90 \mathrm{~kJ} \mathrm{~mol}^{-1}$ at different levels. The planar tetracoordinate carbon atom in the ligand $\mathrm{Si}_{2} \mathrm{C}_{5} \mathrm{H}_{2}$ becomes a hypervalent pentacoordinate carbon upon complexation.
\end{abstract}

Carbon showing hypervalent behavior - either penta or hexa - is rare but not very new to chemists. ${ }^{1-7}$ Non-planar pentacoordination to carbon has already been well established in systems such as $\mathrm{CH}_{5}^{+},{ }^{1,8,9} \mathrm{CLi}_{5},{ }^{10} \mathrm{C}\left(\mathrm{CH}_{3}\right)_{5}^{+},{ }^{11}$ $\left[\left(\mathrm{Ph}_{3} \mathrm{PAu}\right)_{5} \mathrm{C}\right]^{+},{ }^{12}$ and $\mathrm{Si}_{2}\left(\mathrm{CH}_{3}\right)_{7}^{+} \cdot{ }^{13}$ Likewise, non-planar hexacoordination to carbon has been proven in $\mathrm{CLi}_{6},{ }^{10,14}$ $\left[\left(\mathrm{Ph}_{3} \mathrm{PAu}\right)_{6} \mathrm{C}\right]^{2+},{ }^{15}$ and $\mathrm{C}_{6}\left(\mathrm{CH}_{3}\right)_{6}^{2+} \cdot{ }^{16,17}$ Carbon atom having heptavalency is theoretically predicted in trophylium trication, $\mathrm{C}_{7} \mathrm{H}_{7}^{3+}{ }^{18}$ Ferrocene, $\mathrm{Fe}\left(\eta^{5}-\mathrm{C}_{5} \mathrm{H}_{5}\right)_{2}$, is an eminent molecule over the last seven decades. ${ }^{19-22}$ It opened a new avenue called organometallic chemistry, which is continuously growing since 1951. ${ }^{19,23,24}$ Here, using $\mathrm{Si}_{2} \mathrm{C}_{5} \mathrm{H}_{2}$ as a ligand, two ferrocene derivative dication structures are theoretically identified - staggered- $\left[\mathrm{Fe}\left(\mathrm{Si}_{2} \mathrm{C}_{5} \mathrm{H}_{2}\right)_{2}\right]^{2+}\left(\mathbf{1} ; C_{2 h}\right)$ and eclipsed- $\left[\mathrm{Fe}\left(\mathrm{Si}_{2} \mathrm{C}_{5} \mathrm{H}_{2}\right)_{2}\right]^{2+}\left(\mathbf{2} ; C_{2 v}\right)$ - that shows hypervalent nature (pentacoordination) to its ligand carbon atom (see Figure 1). The latter was previously a planar tetracoordinate carbon (ptC) atom ${ }^{25,26}$ in the absence of $\mathrm{Fe}^{2+}$ ion. Both 1 and $\mathbf{2}$ exhibit two hypervalent pentacoordinate carbon atoms due to the formation of a metallocene complex.

In our earlier theoretical work, various isomers of $\mathrm{Si}_{2} \mathrm{C}_{5} \mathrm{H}_{2}$ have been theoretically identified and it was concluded that the molecule with a ptC atom, 2,7disilatricyclo[4.1.0.0 ${ }^{1,3}$ hept-2,4,6-trien-2,7-diyl, is the most stable structure thermodynamically. ${ }^{27}$ The global minimum geometry for $\mathrm{Si}_{2} \mathrm{C}_{5} \mathrm{H}_{2}$ has also been theoretically verified elsewhere through search algorithms. ${ }^{28}$ The kinetic stability of the latter through appropriate dissociation pathways has been analyzed by us in detail recently. ${ }^{29}$ It was proven theoretically that the global minimum isomer of $\mathrm{Si}_{2} \mathrm{C}_{5} \mathrm{H}_{2}$ with a ptC atom is not only thermodynamically stable but also kinetically stable. $^{29}$

Considering the fact that both $\mathbf{1}$ and $\mathbf{2}$ are dications with a net charge of $2+$, it was speculated that $\mathrm{Fe}$ is in +4 oxidation state $\left([\mathrm{Ar}] 3 \mathrm{~d}^{4}\right)$ as in decamethylferrocene dication. ${ }^{30}$ However, the electronic ground states in both $\mathbf{1}$ and $\mathbf{2}$ are not triplets and they are rather singlets. Moreover, the triplets are 70.98 and $16.46 \mathrm{~kJ} \mathrm{~mol}^{-1}$ above singlets in $\mathbf{1}$ and $\mathbf{2}$, respectively, at the $\omega \mathrm{B} 97 \mathrm{X}-\mathrm{D}^{31} / 6-311++\mathrm{G}(2 \mathrm{~d}, 2 \mathrm{p})^{32}-\mathrm{SDD}$ $(\mathrm{Fe})^{33}$ level of theory. Thus, the oxidation state of $\mathrm{Fe}$ in both 1 and 2 is $+2\left([\mathrm{Ar}] 3 \mathrm{~d}^{6}\right)$ and the ligands $\left(\mathrm{Si}_{2} \mathrm{C}_{5} \mathrm{H}_{2}\right)$ are neutral. Overall, these complexes do follow the effective (a)

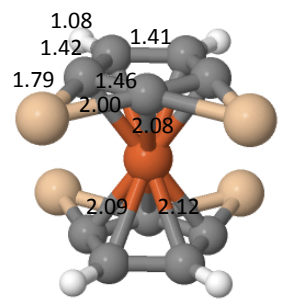

(c)

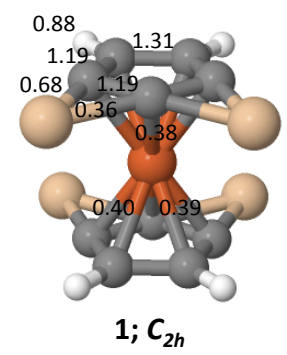

Figure 1. Optimized structures of (a) staggered- and (b) eclipsed-[Fe $\left.\left(\mathrm{Si}_{2} \mathrm{C}_{5} \mathrm{H}_{2}\right)_{2}\right]^{2+}$ (Fe:orange; Si:bisque; C:gray; $\mathrm{H}$ :white). Bond lengths are indicated in $\AA$. Wiberg bond indices are given in (c) and (d), respectively. Calculations are done at the $\omega \mathrm{B} 97 \mathrm{X}-\mathrm{D} / 6-311++\mathrm{G}(2 \mathrm{~d}, 2 \mathrm{p})-\mathrm{SDD}(\mathrm{Fe})$ level of theory.

atomic number $(\mathrm{EAN})$ rule $(\mathrm{EAN}=36)$ and attain the electron configuration of $\mathrm{Kr}$. Therefore, we believe that these complexes could effectively be identified in the laboratory sooner than later provided if $\mathrm{Si}_{2} \mathrm{C}_{5} \mathrm{H}_{2}$ ligand could be prepared.

The C-C bond length in 1 range from 1.41 to $1.46 \AA$ (see Figure 1 (a)) whereas in 2 it varies from 1.42 to $1.47 \AA$ (see Figure 1 (b)). Compared to ferrocene, ${ }^{34}$ where the mean C-C bond length is equal to $1.431 \AA$, these bond lengths are slightly varied, which is reasonable due to the ionic character (dication) in these complexes apart from the presence of silicon atoms. Likewise, the $\mathrm{Fe}-\mathrm{C}$ bond length in $\mathbf{1}$ range from 2.08 to $2.12 \AA$ whereas in 2 it varies from 2.07 to 2.10 $\AA$. In ferrocene, the mean Fe-C bond length is equal to 2.059 $\AA$ and here they are slightly longer. The Si-C bond length connected to the hypervalent carbon is $2.00 \AA$ in $\mathbf{1}$ and 1.99 $\AA$ in $\mathbf{2}$, which reflects its single bond characteristics whereas the $\mathrm{Si}-\mathrm{C}$ bond on the sides are shorter with a bond length of $1.79 \AA$ in both the cases. This shows its double bond characteristics. In principle, the isolated $\mathrm{Si}_{2} \mathrm{C}_{5} \mathrm{H}_{2}$ ligand almost behaves like cyclopentadienyl anion $\left(\mathrm{C}_{5} \mathrm{H}_{5}^{-}\right)$with a slight exception that the former contains $3 \mathrm{c}-2 \mathrm{e} \sigma$ bond around $\mathrm{Si}-$ C-Si region. ${ }^{28,29}$ That is evidently seen even when it makes complexation with $\mathrm{Fe}^{2+}$. The zero-point vibrational energy (ZPVE) corrected-relative energies and Gibbs free energies obtained for $\mathbf{1}$ and $\mathbf{2}$ at different levels are shown in Table 
Table 1. ZPVE-corrected relative energies $\left(\Delta E_{0}\right)$ and thermally corrected Gibbs energies $\left(\Delta G_{298.15}\right)$ of $\mathbf{1}$ and $\mathbf{2}$ at various levels ${ }^{a}$

\begin{tabular}{|c|c|c|c|c|}
\hline \multirow[b]{2}{*}{ Functional } & \multicolumn{2}{|c|}{ isomer 1} & \multicolumn{2}{|c|}{ isomer 2} \\
\hline & $\Delta E_{0}$ & $\Delta G_{298.15}$ & $\Delta E_{0}$ & $\Delta G_{298.15}$ \\
\hline$\omega B 97 X-D$ & 0.00 & 0.00 & 5.61 & 6.54 \\
\hline B3LYP & 0.00 & 0.00 & 4.90 & 6.44 \\
\hline B3LYP-D3BJ & 0.00 & 0.00 & -5.63 & -3.11 \\
\hline TPSSh & 0.00 & 0.00 & -29.08 & -26.52 \\
\hline TPSSh-D3BJ & 0.00 & 0.00 & -30.44 & -29.44 \\
\hline M06-L & 0.00 & 0.00 & -38.11 & -38.02 \\
\hline
\end{tabular}

${ }^{a}$ All values are in $\mathrm{kJ} \mathrm{mol}^{-1}$.

1.

All geometry optimization and frequency calculations for 1 and $\mathbf{2}$ were carried out using 6-311++G(2d,2p) basis set. $^{32}$ For Fe, Stuttgart/Dresden effective core potential of MWF10 and the corresponding atomic natural orbital basis set were used in all calculations. ${ }^{33}$ Various density functionals were used such as B3LYP, ${ }^{35}$ TPSSh, ${ }^{36}$ M06-L, ${ }^{37}$ and $\omega$ B97X-D. ${ }^{31}$ Calculations were also done with empirical dispersion corrections (D3) ${ }^{38}$ with Becke-Johnson damping $(B J)^{39,40}$ (i.e., B3LYP-D3BJ, TPSSh-D3BJ). Natural bond orbital analyses were done using $\omega \mathrm{B} 97 \mathrm{X}-\mathrm{D}$ functional to obtain the natural atomic charges and Wiberg bond indices (WBIs). ${ }^{41}$ All calculations were carried out using the Gaussian program package. ${ }^{42}$

Both 1 and $\mathbf{2}$ contain two hypervalent pentacoordinate carbons. This could be justified with the WBIs calculated (see Figures 1 (c) and (d)) for these two structures. For 1, all WBI values for $\mathrm{Fe}-\mathrm{C}$ are in the range of 0.38 to 0.40 whereas in 2 they are in the range of 0.39 to 0.40 . This indicates that they are indeed single bonds. The hypervalent C-Si WBI values in $\mathbf{1}$ and $\mathbf{2}$ are 0.36 and 0.38 , respectively, reflecting single bond characteristics. WBI values for all $\mathrm{C}-\mathrm{C}$ bond lengths are greater than 1, which indicates resonance stabilization plus double bond characteristics. On the basis of these values, one could certainly conclude that the central carbon atoms are hypervalent (penta) in both the cases. It is emphasized here that each hypervalent carbon obeys the octet-rule as the total WBI for each hypervalent carbon is 3.48 for $\mathbf{1}$ and 3.49 for $\mathbf{2}$. However, some of the bonds ( $\mathrm{Si}-\mathrm{C}$ and $\mathrm{C}-\mathrm{Fe}$ ) are electron-deficient bonds with fewer than two electrons as mentioned elsewhere in the example of $\mathrm{C}\left(\mathrm{CH}_{3}\right)_{5}^{+} \cdot{ }^{11}$ Nevertheless, with appropriate counter ions, it is likely that these new ferrocene derivatives could be isolated in the laboratory opening an avenue for hypervalent carbon chemistry.

Acknowledgement This research work did not receive any specific grant from public or private funding agencies. However, computational support provided at SDSU is gratefully acknowledged.

\section{References}

(1) Tal'rose, V. L.; Lyubimova, A. K. Dokl. Akad. Nauk SSSR 1952, 86, 909-912.

(2) Akiba, K.-y.; Yamashita, M.; Yamamoto, Y.; Nagase, S. J. Am Chem. Soc. 1999, 121, 10644-10645.

(3) Yamashita, M.; Yamamoto, Y.; Akiba, K.-y.; Hashizume, D. Iwasaki, F.; Takagi, N.; Nagase, S. J. Am. Chem. Soc. 2005, $127,4354$.

(4) Akiba, K.-y.; Moriyama, Y.; Mizozoe, M.; Inohara, H.; Nishii, T.; Yamamoto, Y.; Minoura, M.; Hashizume, D.; Iwasaki, F.; Takagi, N.; Ishimura, K.; Nagase, S. J. Am. Chem. Soc. 2005, 127, 5893 .
(5) Fernández, I.; Uggerud, E.; Frenking, G. Chem. Eur. J. 2007, 13, 8620-8626.

(6) Yamaguchi, T.; Yamamoto, Y.; Kinoshita, D.; Akiba, K.-y.; Zhang, Y.; Reed, C. A.; Hashizume, D.; Iwasaki, F. J. Am. Chem. Soc. 2008, 130, 6894-6895.

(7) Lancaster, K. M.; Roemelt, M.; Ettenhuber, P.; Hu, Y. Ribbe, M. W.; Neese, F.; Bergmann, U.; DeBeer, S. Science 2011, 334, 974-977.

(8) Olah, G. A.; White, A. M.; O'Brien, D. H. Chem. Rev. 1970 70,561 .

(9) White, E. T.; Tang, J.; Oka, T. Science 1999, 284, 135-137.

(10) Schleyer, P. v. R.; Wrthwein, E.-U.; Kaufmann, E.; Clark, T. Pople, J. A. J. Am. Chem. Soc. 1983, 105, 5930

(11) McKee, W. C.; Agarwal, J.; Schaefer III, H. F.; Schleyer, P. v. R. Angew. Chem., Int. Ed. 2014, 53, 7875-7878.

(12) Scherbaum, F.; Grohmann, A.; Mller, G.; Schmidbaur, H Angew. Chem., Int. Ed. 1989, 28, 463-465.

(13) Dávalos, J. A.; Herrero, R.; Abboud, J.-L. M.; Mó, O.; Yáez, M Angew. Chem., Int. Ed. 2007, 46, 381.

(14) Kudo, H. Nature 1992, 355, 432.

(15) Scherbaum, F.; Grohmann, A.; Huber, B.; Krger, C.; Schmidbaur, H. Angew. Chem., Int. Ed. 1988, 27, 1544-1546.

(16) Hogeveen, H.; Kwant, P. Tetrahedron Lett. 1973, 14, 16651670 .

(17) Malischewski, M.; Seppelt, K. Angew. Chem., Int. Ed. 2017 $56,368-370$.

(18) Wang, G.; Rahman, A. K. F.; Wang, B. J. Mol. Model. 2018 , $24,116$.

(19) Kealy, T. J.; Pauson, P. L. Nature 1951, 168, 1039-1040.

(20) Wilkinson, G.; Rosenblum, M.; Whiting, M. C.; Woodward, R. B. J. Am. Chem. Soc. 1952, 74, 2125-2126.

(21) Fischer, E. O.; Pfab, W. Z. Naturforschg B 1952, 7, 377-379.

(22) Pfab, W.; Fischer, E. O. Z. Anorg. Allg. Chem. 1953, 274 $316-322$.

(23) Werner, H. Angew. Chem., Int. Ed. 2012, 51, 6052-6058.

(24) Mohammadi, N.; Ganesan, A.; Chantler, C. T.; Wang, F. J. Organomet. Chem. 2012, 713, 51-59.

(25) Monkhorst, H. J. Chem. Commun. (London) 1968, 1111-1112.

(26) Hoffmann, R.; Alder, R. W.; Wilcox, C. F. J. Am. Chem. Soc. 1970, 92, 4992-4993

(27) Thirumoorthy, K.; Cooksy, A. L.; Thimmakondu, V. S. Phys Chem. Chem. Phys. 2020, 22, 5865-5872.

(28) Yañez, O.; Vásquez-Espinal, A.; Pino-Rios, R.; Ferraro, F.; Pan, S.; Osorio, E.; Merino, G.; Tiznado, W. Chem. Commun. 2017, 53, 12112-12115.

(29) Thirumoorthy, K.; Chandrasekaran, V.; Cooksy, A. L.; Thimmakondu, V. S. Chemistry 2021, 3, 13-27.

(30) Malischewski, M.; Adelhardt, M.; Sutter, J.; Meyer, K.; Seppelt, K. Science 2016, 353, 678-682.

(31) Chai, J.-D.; Head-Gordon, M. Phys. Chem. Chem. Phys. 2008, 10, 6615-6620.

(32) Clark, T.; Chandrasekhar, J.; Spitznagel, G. W.; Schleyer, P. v. R. J. Comput. Chem. 1983, 4, 294-301.

(33) Dolg, M.; Wedig, U.; Stoll, H.; Preuss, H. J. Chem. Phys. 1987, $86,866-872$.

(34) Seiler, P.; Dunitz, J. D. Acta Cryst. B 1982, 38, 1741-1745.

(35) Lee, C.; Yang, W.; Parr, R. G. Phys. Rev. B 1988, 37, 785-789.

(36) Tao, J.; Perdew, J. P.; Staroverov, V. N.; Scuseria, G. E. Phys Rev. Lett. 2003, 91, 146401.

(37) Zhao, Y.; Truhlar, D. G. J. Chem. Phys. 2006, 125, 194101.

(38) Grimme, S.; Antony, J.; Ehrlich, S.; Krieg, H. J. Chem. Phys. 2010, 132, 154104.

(39) Becke, A. D.; Johnson, E. R. J. Chem. Phys. 2005, 122, 154104.

(40) Grimme, S.; Ehrlich, S.; Goerigk, L. J. Comput. Chem. 2011, 32, 1456-1465.

(41) Glendening, E. D.; Weinhold, F. J. Comput. Chem. 1998, 19, 593-609.

(42) Frisch, M. J. et al. Gaussian 16 Revision B.01. 2016; Gaussian Inc. Wallingford CT. 